\title{
Ancient heat flow and crustal thickness at Warrego rise, Thaumasia highlands, Mars: Implications for a stratified crust
}

\author{
Javierz Ruiz $^{\mathrm{a}, *}$, Jean-Pierre Williams ${ }^{\mathrm{b}}$, James M. Dohm ${ }^{\mathrm{c}, \mathrm{d}}$, Carlos Fernández ${ }^{\mathrm{e}}$, Valle López ${ }^{\mathrm{f}}$ \\ ${ }^{a}$ Centro de Biología Molecular, CSIC-Universidad Autónoma de Madrid, 28049 Cantoblanco, Madrid, Spain \\ ${ }^{\mathrm{b}}$ Division of Geological and Planetary Sciences, California Institute of Technology, Pasadena, CA 91125, USA \\ ${ }^{\mathrm{c}}$ Department of Hydrology and Water Resources, University of Arizona, Tucson 85721, AZ, USA \\ ${ }^{\mathrm{d}}$ Lunar and Planetary Laboratory, University of Arizona, Tucson 85721, AZ, USA

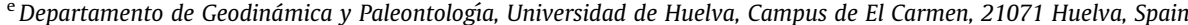 \\ f Instituto Español de Oceanografía, Corazón de María 8, 28002 Madrid, Spain
}

\section{A R T I C L E I N F O}

\section{Article history:}

Received 28 September 2008

Revised 6 May 2009

Accepted 14 May 2009

Available online 23 May 2009

\section{Keywords:}

Mars

Mars, Interior

Tectonics

\begin{abstract}
A B S T R A C T
Heat flow calculations based on geological and/or geophysical indicators can help to constrain the thickness, and potentially the geochemical stratification, of the martian crust. Here we analyze the Warrego rise region, part of the ancient mountain range referred to as the Thaumasia highlands. This region has a crustal thickness much greater than the martian average, as well as estimations of the depth to the brittle-ductile transition beneath two scarps interpreted to be thrust faults. For the local crustal density $\left(2900 \mathrm{~kg} \mathrm{~m}^{-3}\right)$ favored by our analysis of the flexural state of compensation of the local topography, the crustal thickness is at least 70 and $75 \mathrm{~km}$ at the scarp locations. However, for one of the scarp locations our nominal model does not obtain heat flow solutions permitting a homogeneous crust as thick as required. Our results, therefore, suggest that the crust beneath the Warrego rise region is chemically stratified with a heat-producing enriched upper layer thinner than the whole crust. Moreover, if the mantle heat flow (at the time of scarp formation) was higher than 0.3 of the surface heat low, as predicted by thermal history models, then a stratified crust rise seems unavoidable for this region, even if local heatproducing element abundances lower than average or hydrostatic pore pressure are considered. This finding is consistent with a complex geological history, which includes magmatic-driven activity.
\end{abstract}

\section{Introduction}

Calculations of ancient heat flows on Mars based on geological and/or geophysical proxies (e.g., the depth to the brittle-ductile transition or the effective elastic thickness of the lithosphere) have been used, along with information of crustal radioactive heating rates, to obtain constraints on both the thickness and the geochemical stratification, of the martian crust (Ruiz et al., 2006a,b, 2008; Dohm et al., 2009). For example, Ruiz et al. (2008) found a crustal thickness of $43-74 \mathrm{~km}$ for the Amenthes region (at least for the Late Noachian/Early Hesperian time, the time when the large-scale topography and tectonic features used as indicators were formed), by simultaneously considering the brittle-ductile transition depth, the effective elastic thickness, and a reasonable range of values for crustal density, strain rate, and radioactive heating rate. These results are consistent with the range of 38-62 km obtained for the average martian crust by Wieczorek and Zuber (2004) through simultaneously considering several geophysical and geochemical arguments (the crustal thickness in the Amenthes region is $~ 0-$ $5 \mathrm{~km}$ thicker than the average value; Neumann et al., 2004).

The heat flows obtained from the depth to the brittle-ductile transition, combined with the radioactive heating rate, can be used to place an upper limit on the local crustal thickness imposed by the condition of non-negative mantle heat flow (Ruiz et al., 2008). The effective elastic thickness can be used in the same way if this thickness is sufficiently low to preclude lithosphere mantle contributions to the total strength of the lithosphere (Dohm et al., 2009). In this work, we analyze the Warrego rise region, a prominent part of the Thaumasia highlands mountain range on Mars (Fig. 1). The region is of special interest because the regional crustal thickness is estimated to be much thicker than average ( $\sim 25 \mathrm{~km}$ thicker after the crustal models of Neumann et al. (2004, 2008)). The complex geological evolution of Warrego rise region, which includes magmatic and tectonic activity, as well as its distinct topography among the Thaumasia highlands, makes this region an attractive focus for the present research.

Following a description of the physiographic and geologic setting of the Warrego rise region, we calculate heat flows and maximum crustal thicknesses from the depth to the brittle-ductile transition, for which adequate calculations are available for this 


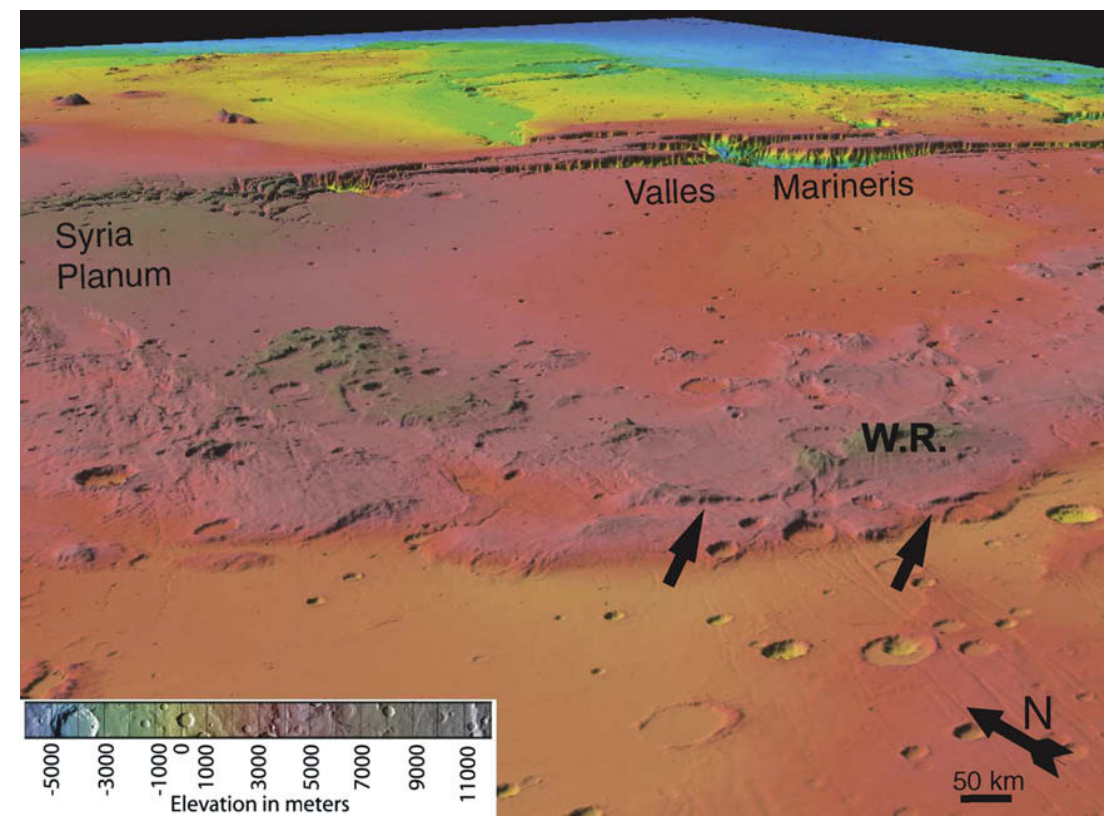

Fig. 1. 3D perspective image using MOLA topography looking obliquely to the northeast across Warrego rise (W.R.) at $10 \times$ vertical exaggeration. The western and eastern scarps interpreted to be thrust faults (Grott et al., 2007) are denoted by black arrows. Warrego rise is the highest promontory within the Noachian Thaumasia highlands mountain range that records complex structure and magnetic signatures, nearby volcanoes, well-developed valley networks of Warrego Valles, pit crater chains, complex rift systems and elongated depressions, impact craters, as well as ridges, fractures, and fault systems of varying trends and erosional/deformational states. Geological investigation indicates a complex geological evolution for the Warrego rise region, which includes magmatic-driven activity (e.g., Dohm et al., 1998, 2001a,b; Grott et al., 2007). Image was produced by Trent Hare of the U.S. Geological Survey, Flagstaff, Arizona.

region (Grott et al., 2007). We then analyze the topography and gravity at Warrego rise in order to obtain constraints on the effective elastic thickness of the lithosphere and crustal thickness and density. Finally, we discuss the implications of our results.

\section{Regional physiographic and geologic setting of Warrego rise and its surrounding}

The Warrego rise, with an elevation of more than $7.6 \mathrm{~km}$ above martian datum, is a prominent part of the ancient Thaumasia highlands, an arcuate mountain range that forms the southern margin of the Thaumasia plateau (Fig. 1; also see Dohm et al., 2001a), a broad $\sim 2900 \mathrm{~km}$ diameter plateau that rises over $4 \mathrm{~km}$ above the surrounding terrain (Dohm et al., 2001b). The Thaumasia highlands are marked by magnetic signatures (e.g., Acuña et al., 1999, 2001; Connerney et al., 1999, 2005; Arkani-Hamed, 2003), complex tectonic structures (Dohm and Tanaka, 1999, 2001a,b, 2007; Grott et al., 2005, 2007; Hauber and Kronberg, 2005; Anguita et al., 2006) (Fig. 2a-c), and valley networks (Fig. 2d) that are especially well-developed along the southern flank of Warrego rise (Gulick and Baker, 1989; Tanaka et al., 1998; Dohm et al., 2001b; Ansan and Mangold, 2006).

The plateau appears to have formed predominately during the Noachain to Early Hesperian, largely by uplift, similar, in part, to that of the terrestrial Colorado Plateau (middle Tertiary) (Dohm et al., 2001b). The Thaumasia highlands mountain range displays characteristics similar to those of the Rocky Mountains (e.g., hog backs, cuestas, thrust faults, etc.; Fig. 2b) that formed during the Laramide orogeny; faulting, volcanic activity, valley dissection, and deep crustal roots are characteristic of all the features (Dohm and Tanaka, 1999; Dohm et al., 2001a,b, 2007; Baker et al., 2007). Differential wind and water erosion has eroded rock materials and structures along parts of the southern edge of the range, resulting in well-defined valley networks, canyons, troughs, hogbacks, and cuestas (Fig. $2 \mathrm{~b}$ and $\mathrm{d}$ ).
Warrego rise, which has been identified as a regional center of tectonic activity (Anderson et al., 2001), forms the southern tip of the Thaumasia Plateau. Geologic evidence indicates that Warrego rise may have developed as a result of Late Noachian-Early Hesperian magmatic-driven activity (Dohm et al., 1998, 2001a,b; Anderson et al., 2001). Evidence for magmatic-driven activity include nearby volcanoes, fault and rift systems (Fig. 2c), collapse pits and depressions, and Late Noachian and Early Hesperian faults that appear deflected about the rise (interpreted to mark an intrusive body at depth which deflected extensional faults about its central core; arrows in Fig. 2c). Valley network development could have been associated with hydrothermal activity (Gulick and Baker, 1989; Tanaka et al., 1998; Dohm et al., 2001b; Schulze-Makuch et al., 2007), and local precipitation (Dohm et al., 2001b; Ansan and Mangold, 2006).

Finally, there are positive gravity anomalies beneath the western Thaumasia highlands (Kiefer, 2008), including the Warrego rise, which are consistent with the presence of intrusive bodies, maybe formed in relation to the overall evolution of the Tharsis magmatic complex (Dohm et al., 1998, 2001a,b, 2007); evidence for such activity includes parts of the Valles Marineris, Solis Planum, and Thaumasia highlands regions.

\section{Calculation of heat flows and maximum crustal thicknesses from faulting depth}

Grott et al. (2007) calculated the depth of faulting beneath two large scarps interpreted to be associated with thrust faults (thought to reach the brittle-ductile transition) in the Thaumasia highlands, one (hereafter the western scarp) located to the west of Coracis Fossae, and another located to the south of Warrego rise (hereafter the eastern scarp; for scarps location see Figs. 1 and 2a and b). These authors modeled the topography above the thrust faults, which they dated to be Noachian in age (between 3.7 and $4.0 \mathrm{Ga}$, based on the Mars cratering chronology of Hartmann and Neukum (2001)), obtaining faulting depths of $27-35$ and $21-28 \mathrm{~km}$ for the western 

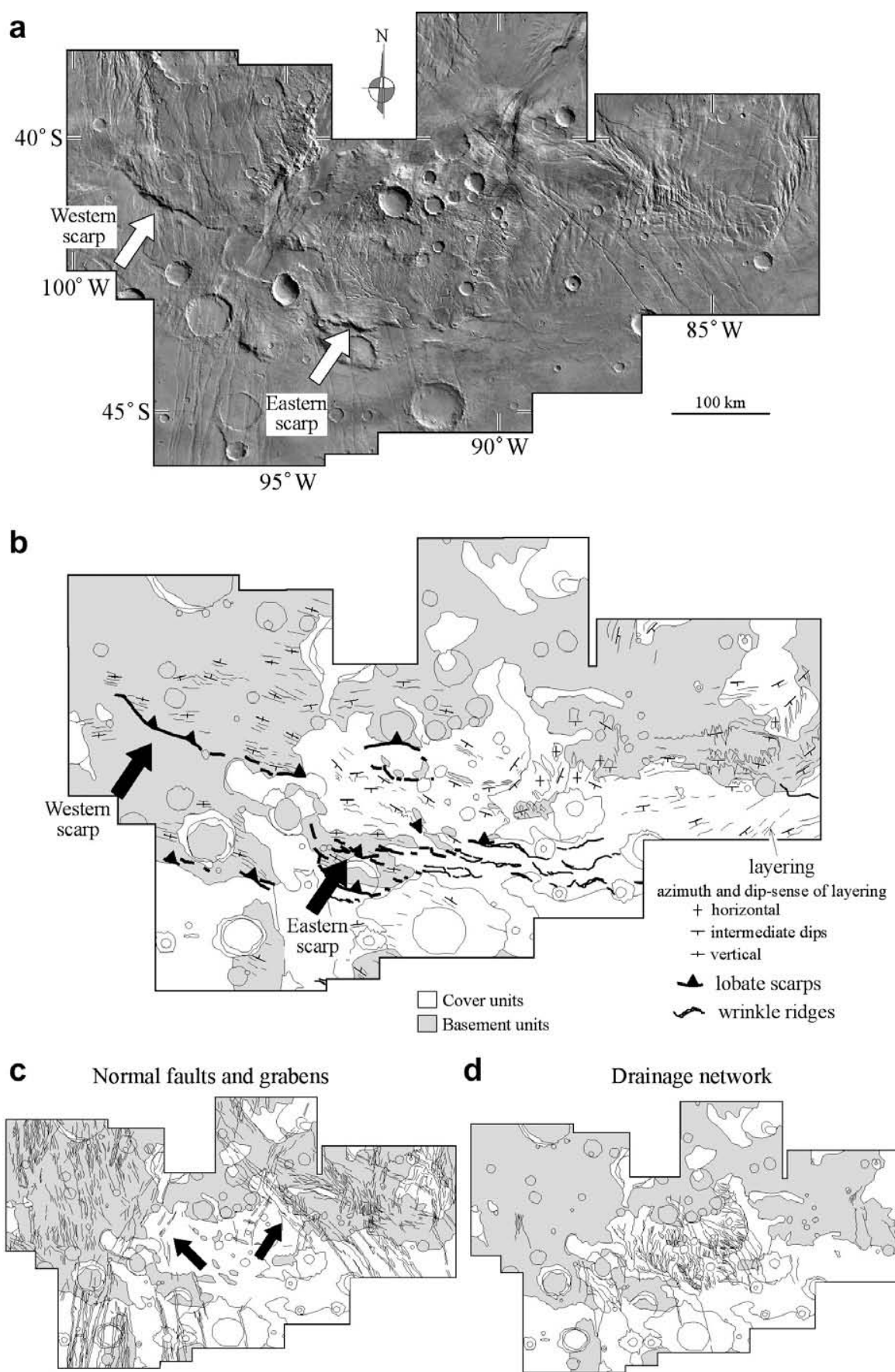

d Drainage network

Fig. 2. (a) Mosaic of Viking images of Warrego rise. (b) Structural sketch of Warrego rise depicting lobate scarps (those studied in this work are marked with black arrows), wrinkle ridges and trend and dip-sense of layering. (c) Normal faults and grabens; arrows depict a deflection of faults about the rise. (d) Drainage pattern.

and eastern scarps, respectively. These faulting depths are similar to those previously obtained for the proposed thrust fault-related Amenthes Rupes scarp, which are in the range between 25 and $35 \mathrm{~km}$ (Schultz and Watters, 2001; Ruiz et al., 2008).

Grott et al. (2007) considered heat flows deduced from the Thaumasia scarps as representative of background values in magmatically inactive areas, obtaining values of 24-36 and 30$46 \mathrm{~mW} \mathrm{~m}^{-2}$ for the western and eastern scarps, respectively. Grott et al. (2005) estimated a heat flow of $54-66 \mathrm{~mW} \mathrm{~m}^{-2}$ from the effective elastic thickness deduced from flexural uplift at the flanks of Coracis Fossae, west of Warrego rise, whose formation dates from the Noachian/Early Hesperian (Dohm et al., 2001b). However, Grott et al. (2007) acknowledge that the results for Coracis Fossae are likely affected by enhanced heat flow related to rifting and magmatic activity, and therefore are not representative of background values in magmatically inactive areas. These estimations were performed without taking into account the presence of radioactive heat sources in the crust. However, the use of crustal heat sources in this kind of calculation increases the obtained surface heat flows and potentially places constraints on the thickness and differentiation state of the crust (Ruiz et al., 2006a,b, 2008; Dohm et al., 2009), which is the aim of this paper. Thus, we use estimated faulting depths beneath the western and eastern scarps in order to calculate heat flows (valid for the time when the faults were formed) by taking into account crustal heat sources, following the procedure described in Ruiz et al. (2008). 
The temperature at the brittle-ductile transition depth can be obtained from the temperature dependence of ductile strength by equating the brittle and ductile strength for the depth $z=z_{B D T}$ (where $z_{B D T}$ is the depth to the brittle-ductile transition). The brittle strength is calculated for zero pore pressure, according to the expression

$\left(\sigma_{1}-\sigma_{3}\right)_{b}=\alpha \rho_{c} g z$,

where $\alpha$ is a coefficient depending on the stress regime (which is 3 for pure compression, appropriate for thrust faulting; e.g., Ranalli, 1997), $\rho_{c}$ is the density of the crust, $g$ is the acceleration due to the gravity (3.72 $\mathrm{ms}^{-2}$ for Mars), and $z$ is the depth. The ductile strength is given by

$\left(\sigma_{1}-\sigma_{3}\right)_{d}=\left(\frac{\dot{e}}{A}\right)^{1 / n} \exp \left(\frac{Q}{n R T}\right)$

where $\dot{e}$ is the strain rate, $A$ and $n$ are laboratory-determined constants, $Q$ is the activation energy of creep, $R\left(=8.31447 \mathrm{~J} \mathrm{~mol}^{-1} \mathrm{~K}^{-1}\right)$ is the gas constant, and $T$ is the absolute temperature. If crustal heat sources are assumed to be homogeneously distributed, then the surface heat flow is calculated from

$F=\frac{k_{c}\left(T_{B D T}-T_{s}\right)}{z_{B D T}}+\frac{z_{B D T} \rho_{c} H}{2}$,

where $k_{c}$ is the thermal conductivity of the crust, $T_{B D T}$ is the temperature at the brittle-ductile transition, $T_{s}$ is the surface temperature, and $H$ is the heat production rate by mass unity.

We use a surface temperature of $220 \mathrm{~K}$, the present-day mean surface temperature (Kieffer et al., 1977), and a thermal conductivity of the crust of $2 \mathrm{~W} \mathrm{~m}^{-1} \mathrm{~K}^{-1}$, appropriate for basaltic rocks (e.g., Clifford, 1993; Grott et al., 2005) and for a wide variety of possible crustal rocks at temperatures of several hundreds of degrees centigrade (e.g., Bonner et al., 2003). For the crustal volumetric heating rate we use potassium and thorium abundances of 3300 and $0.62 \mathrm{ppm}$, respectively, average values deduced for the upper $1 / 3$ meters of the martian surface from Mars Odyssey GRS data (Taylor et al., 2006). These values are higher than $K$ and Th abundances in SNC meteorites, but the later are probably not representative of the martian crust (Taylor et al., 2006). For uranium abundance, we use a $\mathrm{Th} / \mathrm{U}$ ratio of 3.6 deduced from SNC meteorite geochemistry (McLennan, 2003). We calculate crustal heat production rates by using decay constants from Van Schmus (1995), obtaining heat production rates between 1.64 and $1.91 \times 10^{-10} \mathrm{~W} \mathrm{~kg}^{-1}$ for 3.7 and $4.0 \mathrm{Ga}$, respectively. For creep parameters of the martian crust, we use the constants for the flow law of diabase: $A=0.0612 \mathrm{MPa}^{-n} \mathrm{~s}^{-1}$, $n=3.05$ and $Q=276 \mathrm{~kJ} \mathrm{~mol}^{-1}$ (Caristan, 1982). The use of a wet diabase for the martian crust is consistent with extensive evidence for water-related geological activity during early Mars (e.g., Scott et al., 1995; Head et al., 2001; Fairén et al., 2003).

Strain rates of $10^{-16}$ and $10^{-19} \mathrm{~s}^{-1}$ are used in the calculations, based on a range usually considered for Mars (e.g., McGovern et al., 2002, 2004; Ruiz et al., 2008). Finally, we perform the calculations for crustal densities of 2700,2900 and $3100 \mathrm{~kg} \mathrm{~m}^{-3}$. The lowest and highest values place bounds to a conservative range for the density of the martian crust (e.g., Wieczorek and Zuber, 2004), whereas the central value, which is frequently used for Mars (e.g., Zuber et al., 2000; McGovern et al., 2002), corresponds to the nominal density used in the crustal model of Neumann et al. (2004, 2008).

Fig. 3 shows the surface heat flow, as a function of the depth to the brittle-ductile transition depth and strain and heat production rates, calculated for a representative crustal density of $2900 \mathrm{~kg} \mathrm{~m}^{-3}$. For whichever combination of strain rate, heat production rate, and brittle-ductile transition depth, the heat flow obtained by using crustal densities of $2700 \mathrm{~kg} \mathrm{~m}^{-3}$ ( or $3100 \mathrm{~kg} \mathrm{~m}^{-3}$ )

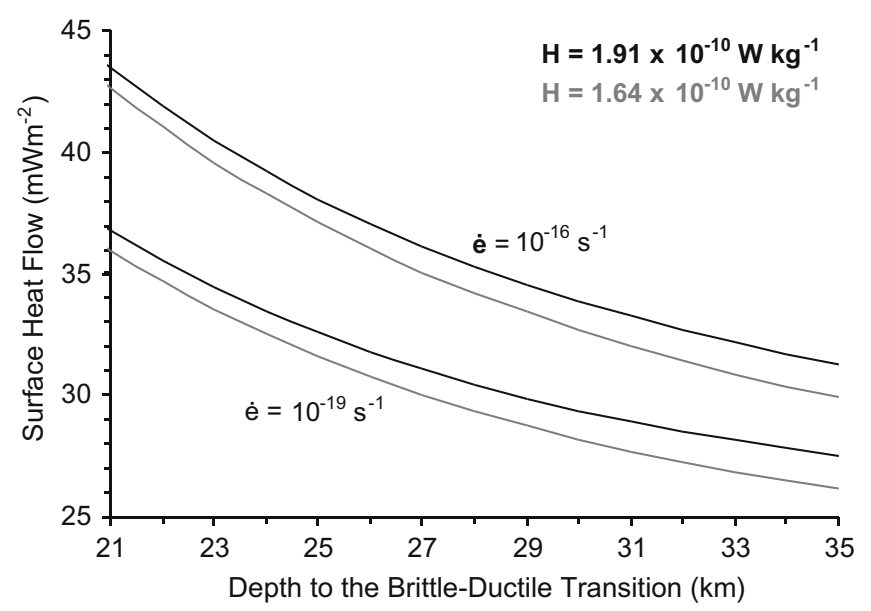

Fig. 3. Surface heat flow as a function of the depth to the brittle-ductile transition, and strain and heat production rates, calculated for a crustal density of $2900 \mathrm{~kg} \mathrm{~m}^{-3}$.

are lower (higher) than those shown in Fig. 3, although the difference is always lower than $1 \mathrm{~mW} \mathrm{~m}^{-2}$. For thrust faulting depths between 21 and $35 \mathrm{~km}$, the heat flow varies between 26 and $44 \mathrm{~mW} \mathrm{~m}^{-2}$, depending on both strain and heat production rates. Our values are somewhat lower than those found by Grott et al. (2007) for linear thermal gradients because these authors used faster strain rates and the friction coefficient rather than the stressdependent coefficient for compression.

A contribution to the surface heat flow is due to radioactive heating in the crust, whereas the remainder must reach the crust from the mantle. Thus, the surface heat flow obtained from Eq. (3), combined with the condition of non-negative mantle heat flow, impose upper limits (given by $F / \rho_{c} H$ ) on the crustal thickness or, at least, on the thickness of an upper heat-producing element-enriched layer. Maximum permitted crustal thicknesses are obtained for higher strain rates and lower heat production rates. Thus, Fig. 4 shows maximum permitted crustal thicknesses for $\dot{e}=10^{-16} \mathrm{~s}^{-1}$, $H=1.64 \times 10^{-10} \mathrm{~W} \mathrm{~kg}^{-1}$, and crustal densities of 2700,2900 and $3100 \mathrm{~kg} \mathrm{~m}^{-3}$, as a function of the brittle-ductile transition depth. For thrust faulting depths between 21 and $35 \mathrm{~km}$, the maximum permitted crustal thicknesses ranges between 59 and $96 \mathrm{~km}$.

In the next section, we constrain the crustal thickness and density from gravity and topography data. In Section 5 we present the

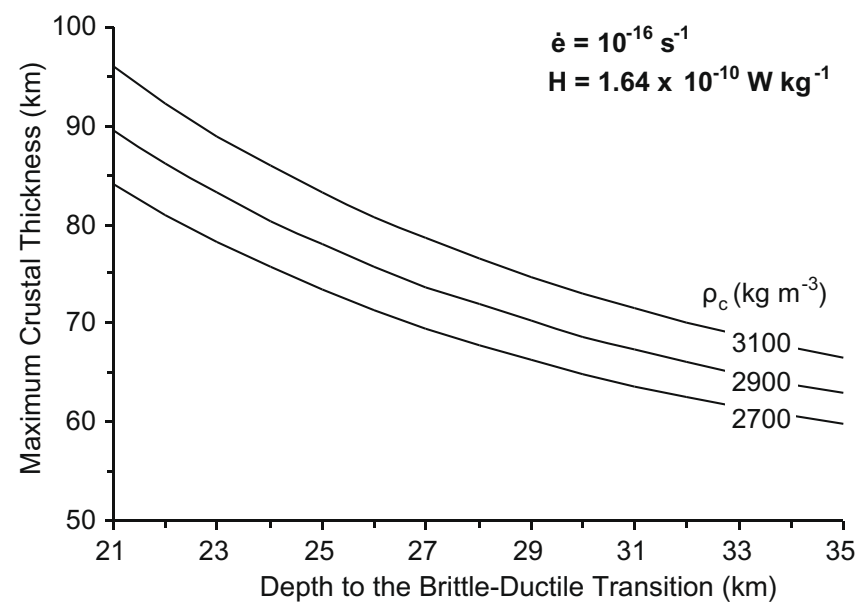

Fig. 4. Maximum permitted crustal thicknesses obtained from surface heat flows, $\dot{e}=10^{-16} \mathrm{~s}^{-1}, H=1.64 \times 10^{-10} \mathrm{~W} \mathrm{~kg}^{-1}$ and the condition of non-negative mantle heat flow, as a function of the brittle-ductile transition depth and crustal density. 
implications of our results, as well as discuss the effect of the crustal thermal conductivity, heat-producing elements abundances and rheology on these results. We also discuss, in Section 6, the robustness of our results.

\section{Constraint on effective elastic thickness, crustal thickness, and crustal density}

We use spherical harmonic models of the topography (Mars2000; Smith et al., 2001) and gravity (jgm95j01; Konopliv et al., 2006) to estimate the effective elastic thickness of the lithosphere, as a function of the crustal thickness and density, for the Warrego rise. In our calculations, we use free-air gravity anomaly and finite-amplitude topography for harmonic degrees 5-75, thereby excluding degrees dominated by the hemisphere-scale Tharsis bulge. From topography, we determine gravity employing a gravity-topography transfer function derived from the formulation of Turcotte et al. (1981) for bending and membrane stresses in a thin-elastic shell. If it is assumed that the topography results from top loading at the surface, the gravity is related to the topography by

$g_{i l m}=4 \pi G \rho_{c}\left(\frac{l+1}{2 l+1}\right) h_{i l m}\left[1-\left(1-\frac{t_{c r}}{R}\right)^{l+2} \alpha_{l}^{t}\right]$,

where $g_{\text {ilm }}$ and $h_{\text {ilm }}$ are harmonic coefficients for gravity and topography, respectively, for degree $l$ and order $m, G$ is the gravitational constant, and $t_{c r}$ is the reference crustal thickness. The harmonic coefficients for topography are

$h_{i l m}=\sum_{n=1}^{l+3} \frac{\prod_{j=1}^{n}(l+4-j)}{(l+3) n !}{ }^{n} h_{i l m}^{\prime}$,

where successive powers of topography, $H^{n}$, are expanded into spherical harmonics (Wieczorek and Phillips, 1998; McKenzie et al., 2002) in an analogous manner to the Cartesian case of Parker (1972). The function $\alpha_{l}^{t}$ represents the degree of compensation for a given degree harmonic

$\alpha_{l}^{t}=\frac{l(l+1)-(1-v)}{\sigma\left[l^{3}(l+1)^{3}-4 l^{2}(l+1)^{2}+4 l(l+1)\right]+\tau[l(l+1)-2]+l(l+1)-(1-v)}$,

where $\sigma=D / R^{4} g \rho$ and $\tau=E T_{e} / R^{2} g \rho$. The flexural rigidity, $D$, is a function of the effective elastic thickness of the lithosphere, $T_{e}$, and the elastic constants Young's modulus, $E=10^{11} \mathrm{~Pa}$, and Poisson's ratio, $v=0.25$. For top loading, $\rho=\rho_{m}-\rho_{c}$ where the mantle density, $\rho_{m}=3400 \mathrm{~kg} \mathrm{~m}^{-3}$, is held constant and we vary the crust density $\rho_{c}$. The topography is then related to the deflection of the lithosphere by

$w^{t}=-\frac{\rho_{c}}{\rho_{m}-\rho_{c}} \alpha_{l}^{t} h^{t}$.

We have dropped the subscripts for convenience. For bottom loading, $h_{b}$ represents the deflection of the lithosphere due to a subsurface load of thickness $w_{b}$ similar to the approach of McGovern et al. (2002). Assuming the load density is $\rho_{m}-\rho_{c}$,

$h^{b}=-\frac{\rho_{m}-\rho_{c}}{\rho_{m}} \alpha_{l}^{b t} w^{b}$,

where $\alpha_{l}^{b}$ is that of Eq. (6) with $\rho=\rho_{m}$ now. We then combine surface and subsurface loading where the ratio of the initial subsurface load to the initial surface load is

$f=-\frac{w^{b}\left(\rho_{m}-\rho_{c}\right)}{h_{i} \rho_{c}}$

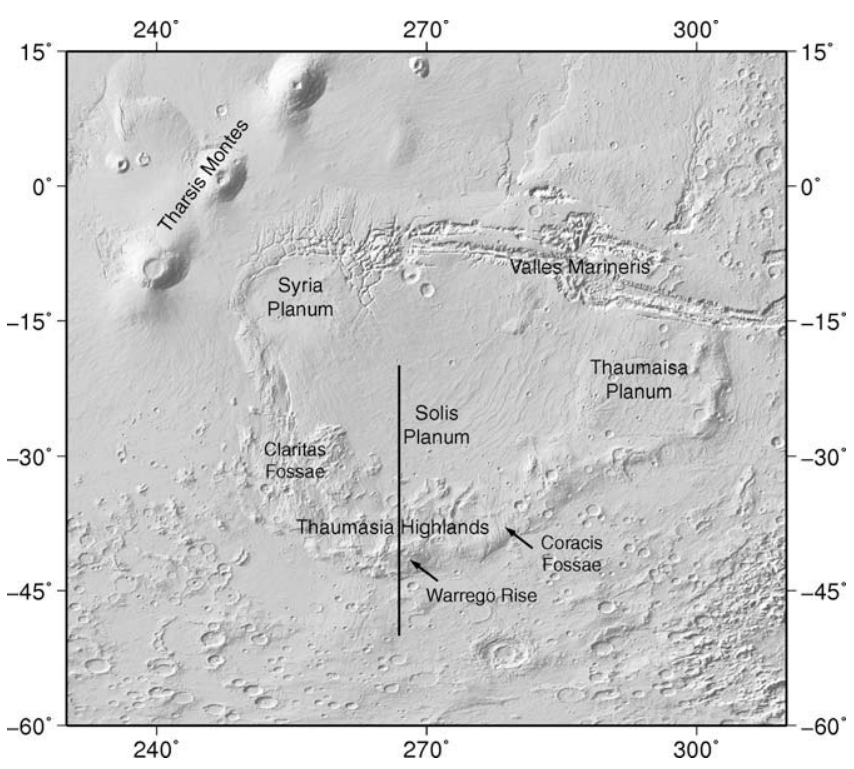

Fig. 5. MOLA topographic map showing the transect line of the topographic profile used for determine the misfit between the observed and modeled gravity in the Warrego rise region of the Thaumasia highlands mountain range.

where $h_{i}$ is the initial surface load $h^{t}-w^{t}$. The observed surface relief is then the result of relief produced by both surface and subsurface loading $h=h^{t}+h^{b}$ from which an expression relating surface relief to the subsurface load thickness is obtained,

$h=-w^{b}\left(\rho_{m}-\rho_{c}\right) \Phi$,

where

$\Phi=\left[\frac{1}{f \rho_{c}\left(1-\frac{\rho_{c}}{\rho_{m}-\rho_{c}} \alpha_{l}^{t}\right)}-\frac{\alpha_{l}^{b}}{\rho_{m}}\right]$.

From this we determine the gravity coefficients,

$g=4 \pi G\left(\frac{l+1}{2 l+1}\right) h\left\{\rho_{c}\left(1-\gamma_{l} \alpha_{l}^{t}\right)-\frac{\gamma_{l}}{\Phi}\left[\frac{\rho_{c}}{\rho_{m}} \alpha_{l}^{b}\left(1-\alpha_{l}^{t}\right)+\left(1-\alpha_{l}^{b}\right)\right]\right\}$,

accounting for the surface and subsurface load force and the deformation of the surface and Moho from these loads where we have assumed the subsurface loading occurs at a depth, $t_{c r}$, corresponding to the Moho and

$\gamma_{l}=\left(1+\frac{t_{c r}}{R_{p}}\right)^{l+2}$

When $f=0, \Phi^{-1}=0$ and we recover Eq. (4) for surface loading only.

We determine the RMS misfit between the observed gravity and the modeled gravity for a latitudinal profile selected specifically to transect the Warrego rise (see Fig. 5 for ground track). The RMS misfit is calculated between $37^{\circ} \mathrm{S}$ and $43^{\circ} \mathrm{S}$, in order to isolate the Thaumasia highlands in this profile.

Results for $f=0$ and crustal densities of 2700, 2900 and $3100 \mathrm{~kg} \mathrm{~m}^{-3}$ are shown in elastic thickness versus crustal thickness plots (Fig. 6). In general, the misfit is rather large: The uncertainty in the gravity is no more than $10 \mathrm{mGals}$ (Wieczorek, 2007), but the RMS misfit is never less than $10 \mathrm{mGal}$ for any parameter combination. This is due to an apparent offset between the topography and the gravity over the southern Thaumasia highlands (Fig. 7). This offset was previously observed through the analysis of Line-of-Sight acceleration profiles taken by Mars Global Surveyor spacecraft over the Thaumasia highlands (Williams et al., 

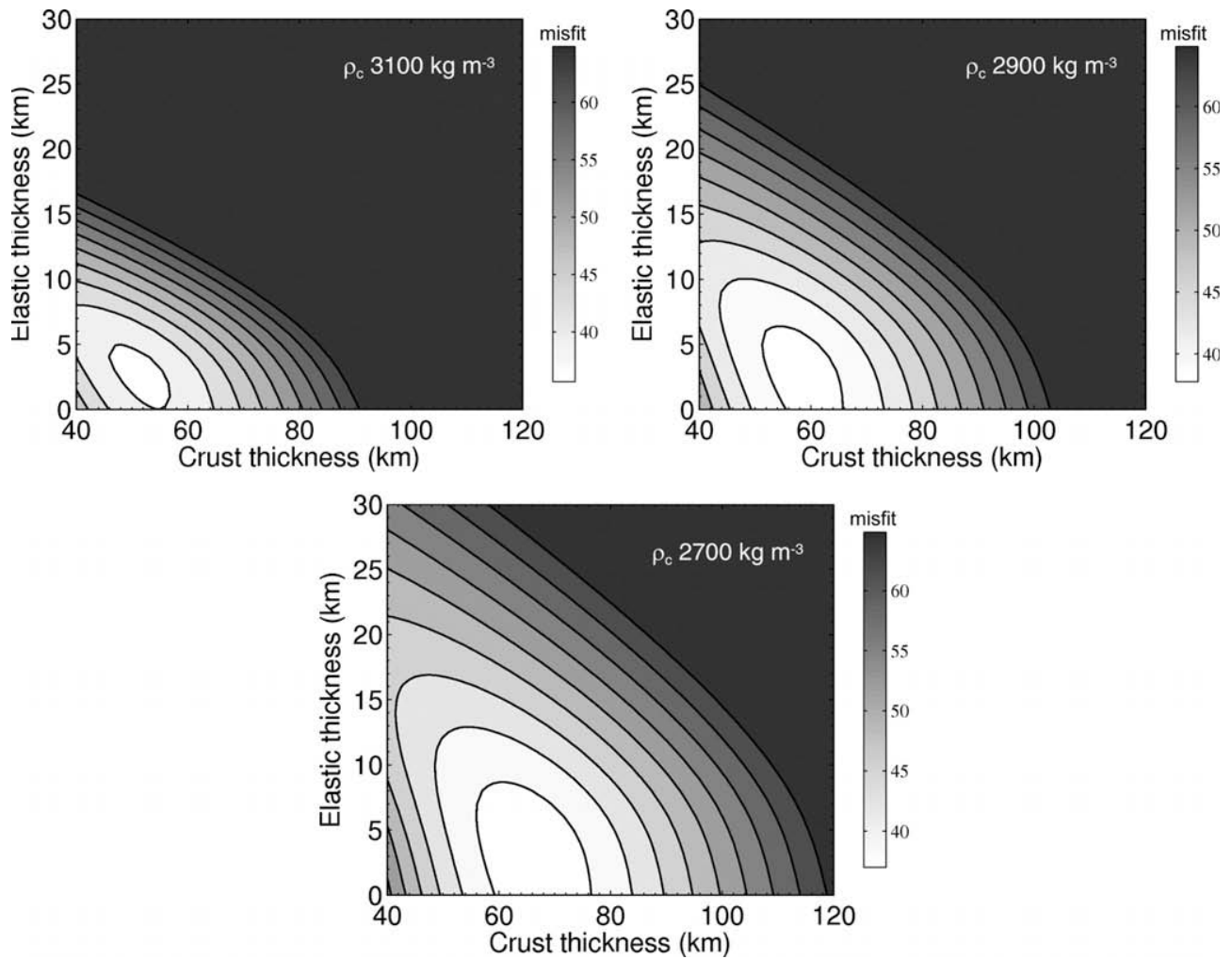

Fig. 6. Contours of RMS misfit between the observed gravity and the modeled gravity for the profile shown in Fig. 5, calculated for $f=0$, and shown as a function of the crustal thickness and effective elastic thickness for crustal densities of 3100,2900 and $2700 \mathrm{~kg} \mathrm{~m}^{-3}$. Contour levels are 1.1 times the minimum misfit.
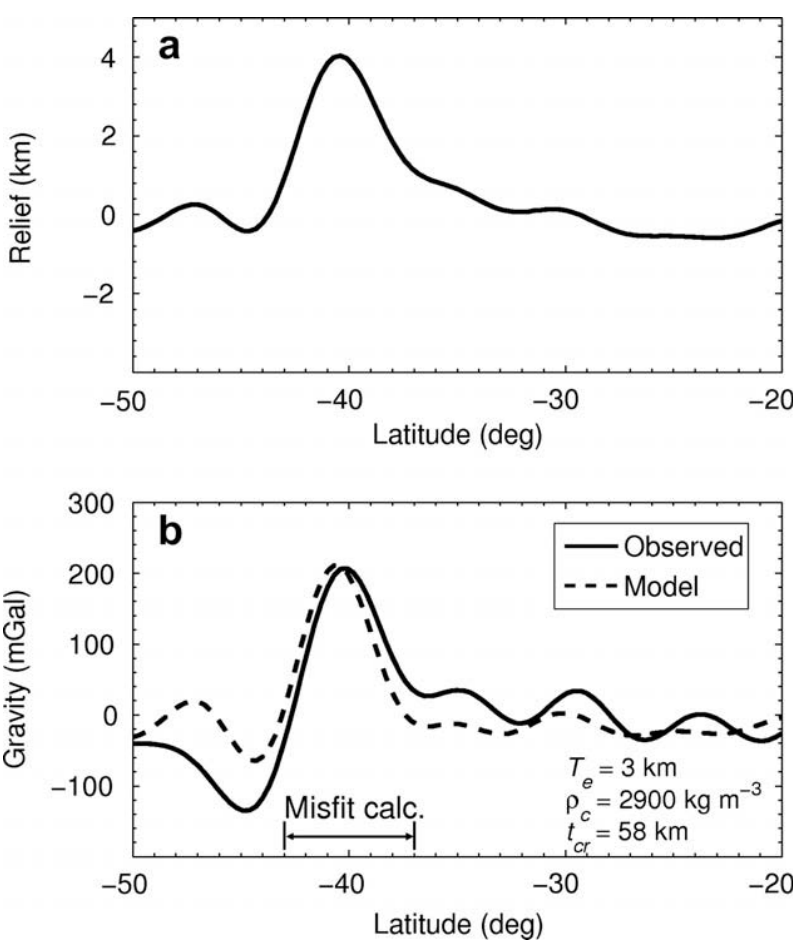

Fig. 7. (a) North-trending MOLA topographic profile (transect shown in Fig. 5) used in this investigation. (b) observed gravity (solid) and best-fit model (dashed). Misfit was calculated between -43 and -37 degrees latitude. There is an offset between the observed gravity and gravity predicted using topography in the southern Thaumasia Highlands.

2008), and could be explained, in part, by the highlands having experienced a significant amount of erosion or subsequent loading of the lithosphere by flood basalts in the interior part of the Thaumasia plateau (Williams et al., 2008).

Fig. 6 shows that effective elastic thicknesses lower than $\sim 10 \mathrm{~km}$ are favored for $f=0$. Previous work has favored similarly low values for other Early Noachian terrains (e.g., McGovern et al., 2002, 2004; Kronberg et al., 2007), or for the southern highlands taken as a whole (McKenzie et al., 2002). This would be consistent with a very early origin for Thaumasia highlands, when the heat flow was still high. Fig. 6 also shows that the thickness of the reference crust decreases with increasing crustal density. Crustal thicknesses between $\sim 40$ and $\sim 80 \mathrm{~km}$ are favored (for misfit $\sim 1.15$ times the minimum misfit), though misfit quality precludes us from obtaining more precise constraints. Similar results and density-related trends are obtained by Wieczorek and Zuber (2004) from an analysis of geoid to topography ratios of the southern highlands. Our values are lower limits because larger crustal thicknesses and effective elastic thicknesses are obtained if bottom loading is assumed (Fig. 8). There is a general trade-off between $t_{c r}$, $T_{e}$, and $f$. Increasing $t_{c r}$ or decreasing $T_{e}$ will reduce the influence $f$ has on the gravity resulting in an increase in $f$ in the model to compensate. As a result, bottom loading on a strong plate can yield similar admittances to top loading on a weak plate. An increased effective elastic thickness would be consistent with a post-Early Noachian establishment of the observed gravity/topography relation in the Warrego rise.

Figs. 6 and 8 show that the effective elastic thickness is not well constrained for the Warrego rise region. So, the heat flow range deduced from the Thaumasia highlands scarps is more restrictive than the equivalent range that could be deduced from the effective elastic thickness. Moreover, a zero value for the effective elastic thickness is permissible (Fig. 6). This prevents a heat flow upper limit from being determined from $T_{e}$, which in turn precludes the possibility of calculating maximum crustal thicknesses following a similar procedure to that used in Section 3. Heat flow calculations 

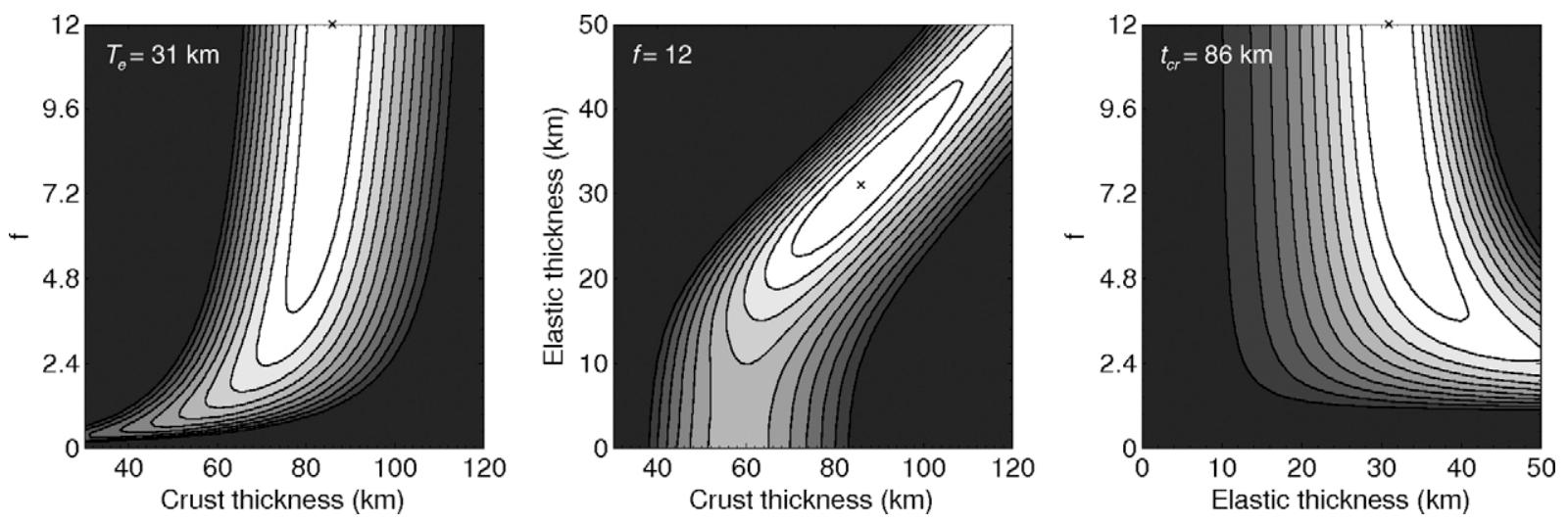

Fig. 8. Examples of contours of RMS misfit between the observed gravity and the modeled gravity for the profile shown in Fig. 5 and the nominal crustal density of $2900 \mathrm{~kg} \mathrm{~m}^{-3}$, shown for (left) $f$ as a function of crustal thickness ( $T_{e}$ fixed), (center) effective elastic thickness as a function of crustal thickness $(f$ fixed), and (right) $f$ as a function of the effective elastic thickness (crust thickness fixed).

based on effective elastic thicknesses cannot, therefore, be used for the purposes of the present work.

For the nominal density of $2900 \mathrm{~kg} \mathrm{~m}^{-3}$, we obtain a reference crustal thickness of $\sim 50-70 \mathrm{~km}$ for $f=0$. The crustal models and maps of Neumann et al. (2004, 2008) assume a mean crustal thickness of $45 \mathrm{~km}$. This value gives a crustal thickness of $\sim 6 \mathrm{~km}$ in the center of Isidis basin, consistent with geological evidence for a crust with a thickness of at least $5 \mathrm{~km}$ in this location (see Neumann et al., 2004). Similarly, calculations of heat flows from effective elastic thicknesses and faulting depths for the Amenthes region (Ruiz et al., 2008) indicate an average crustal thickness for Mars of $\sim 45-65 \mathrm{~km}$ if the crustal density is taken as of $2900 \mathrm{~kg} \mathrm{~m}^{-3}$. Thus, for a crustal density of $2900 \mathrm{~kg} \mathrm{~m}^{-3}, 45 \mathrm{~km}$ is a reasonable lower limit for the average thickness of the martian crust. Local crustal thicknesses of Neumann et al. (2008), which would be 70 and $75 \mathrm{~km}$ at the locations of the eastern and western scarps, are therefore appropriate lower limits for comparison with our results in the previous section.

Global models for crustal densities of 2700 and $3100 \mathrm{~kg} \mathrm{~m}^{-3}$ fit both a crustal thickness of $5 \mathrm{~km}$ at the central part of the Isidis basin and the observed Bouguer anomaly for average crustal thicknesses of 35 and $65 \mathrm{~km}$, respectively (Neumann et al., 2004). These values are lower limits. For the $3100 \mathrm{~kg} \mathrm{~m}^{-3}$ case, the lower limit of $65 \mathrm{~km}$ is higher than our lower limit results in Fig. 6, but is beyond (although slightly) the upper limit obtained by Wieczorek and Zuber (2004). Assuming that the southern highlands as a whole are isostatically supported (Wieczorek and Zuber, 2004) an average crustal thickness of $65 \mathrm{~km}$ would imply crustal thicknesses of 103 and $110 \mathrm{~km}$ at the locations of the eastern and western scarps.

For the $2700 \mathrm{~kg} \mathrm{~m}^{-3}$ case, reference crustal thicknesses shown in Fig. 6 are higher than $35 \mathrm{~km}$, and we therefore find that $50 \mathrm{~km}$ is a reasonable lower limit for the average crustal thickness (which is also consistent with the lower limit of $47 \mathrm{~km}$ obtained from geoid/topography ratios of the southern highlands; Wieczorek and Zuber, 2004); in this case, the assumption of isostasy for the southern highlands would imply crustal thicknesses of 69 and $73 \mathrm{~km}$ at the locations of the eastern and western scarps. However, topography/admittance studies of Solis Planum, north of Thaumasia highlands (McGovern et al., 2002, 2004), or the southern highlands taken as a whole (McKenzie et al., 2002) support crustal densities close to, or slightly higher than, $2900 \mathrm{~kg} \mathrm{~m}^{-3}$.

Thus, geophysical constraints for crustal density does not favor values in the lower end of the considered range, whereas the constraints for average crustal thickness are scarcely reconcilable with a crustal density of $3100 \mathrm{~kg} \mathrm{~m}^{-3}$. On the other hand, a crustal den- sity close to $2900 \mathrm{~kg} \mathrm{~m}^{-3}$ is consistent with both inferred crustal density and thickness ranges.

\section{Results}

The maximum permitted crustal thicknesses calculated in Section 3 and shown in Fig. 4 can be compared with crustal thicknesses beneath the western and eastern scarps. For $\rho_{c}=2900 \mathrm{~kg} \mathrm{~m}^{-3}$, maximum permitted crustal thicknesses are higher than the local lower limit of $70 \mathrm{~km}$, based on the crustal thickness model of Neumann et al. (2004), at the eastern scarp location. However, the maximum permitted crustal thicknesses for the western scarp are always lower than $75 \mathrm{~km}$. The condition of a homogeneous crust on Thaumasia highlands is therefore not satisfied in the western scarp location.

The condition of zero mantle heat flow $\left(\rho_{c} H t_{c l} / F=1\right.$, where $t_{c l}$ is the local crustal thickness) used to calculate maximum permitted crustal thicknesses is very restrictive. Fig. 9 shows permitted crustal thicknesses if the mantle heat flow is 0 and 0.25 times the surface heat low (i.e., $\rho_{c} H t_{c l} / F=1$ and 0.75 , respectively). It is clear that the crust cannot be homogeneous if the mantle heat flow

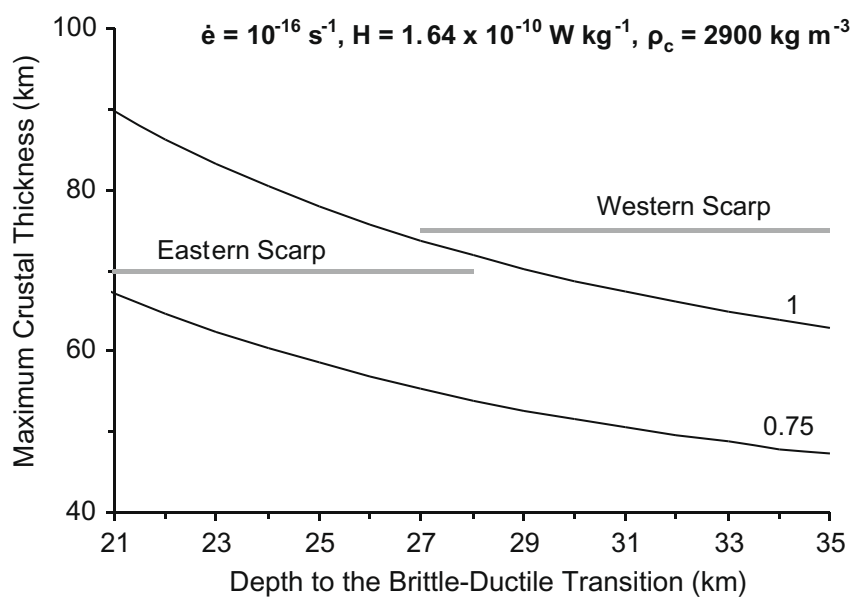

Fig. 9. Maximum permitted crustal thicknesses beneath Thaumasia highlands (solid curves) for $\rho_{c} H t_{c l} / F$ (the fraction of the surface heat flow originated from crustal heat sources) $=1$ and 0.75 shown as a function of the brittle-ductile transition depth. Lower limits to the crustal thickness beneath the western and eastern scarps (based on global maps in Neumann et al. (2008)) are indicated by horizontal thick gray lines, drawn for the ranges for the depth to the brittle-ductile transition obtained by Grott et al. (2007) for these scarps. 
contributes more than about a quarter of the total surface heat flow, even in the case for the eastern scarp. Previous heat flow calculations suggest that a substantial fraction of radioactive elements is placed in the crust (Ruiz et al., 2006a,b, 2008), although these results permit a large range of possible mantle heat flows. On the other hand, thermal history models including crustal growth and radioactive element concentration due to mantle melting (e.g., Hauck and Phillips, 2002), find a mantle heat flow representing $\sim 0.7$ of the total surface heat flow for $\sim 3.5-4 \mathrm{Ga}$. Thus, although a mantle heat flow/surface heat flow ratio as low as 0.25 cannot be discarded, it would be unlikely, which in turn reinforces our argument favoring a stratified crust at Warrego rise.

\section{Discussion: Robustness of the results}

Parmentier and Zuber (2007) have suggested that vigorous hydrothermal circulation could greatly enhance heat transfer through the upper crust, even by a factor 2 or 3 , if the porosity of the martian crust is interconnected and water saturated to a sufficient depth. In this case the argument for a stratified crust presented in this work would be weaker.

The possibility of hydrothermally enhanced heat flow on early Mars was proposed as an explanation for the present-day survival of large wavelength crustal thickness variations (Parmentier and Zuber, 2007). Indeed, temperatures obtained for base of the crust through extrapolation of linear thermal gradients obtained from the effective elastic thickness of the lithosphere (e.g., McGovern et al., 2002, 2004) are high, which should permit relaxation of crustal thickness variations (Zuber et al., 2000). The effect of crustal heat sources on heat flows and temperature profiles deduced from effective elastic thicknesses was analyzed by Ruiz et al. (2006a). These authors found that if a substantial fraction of radioactive heat sources is located in the crust (as suggested for Mars; e.g., Taylor and McLennan, 2009), temperature profiles consistent with the elastic thickness of the lithosphere clearly give lower temperatures at the crust/mantle interphase than those deduced using linear thermal gradients. Thus, the maintenance of large-scale crustal thickness variations can be explained without appeal to strong hydrothermal cooling.

On the other hand, the presence of phyllosilicates exposed on deeply eroded terrains and impact craters and ejecta on the southern highlands has been interpreted as evidence of an abrupt thermal gradient, and hence for hydrothermal cooling (e.g., Parmentier et al., 2008; Fraeman et al., 2009). However, a preliminary study (Fraeman et al., 2009) of the proportions of smectite, and chlorite/phrenite and muscovite/illite (which are generally higher temperature minerals than smectite) as a function of crater depth, and therefore excavation depth, does not find a clear correlation between phase mineral temperature and inferred pre-impact depth; rather, high temperature mineral seem more abundant in shallower depth.

Thus, the possibility of a strong early hydrothermal cooling of the martian crust is very attractive, but it remains speculative. Hydrothermal circulation could have existed extensively on Mars, possibly related to the background heat flow (Travis et al., 2003; Hanna and Phillips, 2005) or to magma/water interactions (e.g., Dohm et al., 2009) but it does not necessarily imply a severe cooling at crustal scale.

With independence of the above discussion, if liquid water was present in the upper crust a pore pressure would have existed. This in turn would imply a decrease of the brittle strength, and hence an increase of both the surface heat flow and the maximum permitted crustal thickness. Again, it is unknown if liquid water was present in sufficient amount to significantly alter our results. We will return to this point.
Other factors could potentially affect the robustness of the evidence for a stratified crust beneath Warrego rise. For example, potassium and thorium abundances for the Thaumasia highlands suggested by GRS maps are somewhat lower than average (see maps in Taylor et al., 2006; Boynton et al., 2007). This may be due to a number of factors including the size of the mountain range with respect to the spatial relation of the GRS; whereas the range is about $500 \mathrm{k}$ wide and Warrego rise is about $200 \mathrm{~km}$ across, GRS provides a spatial resolution approximately equal to the altitude
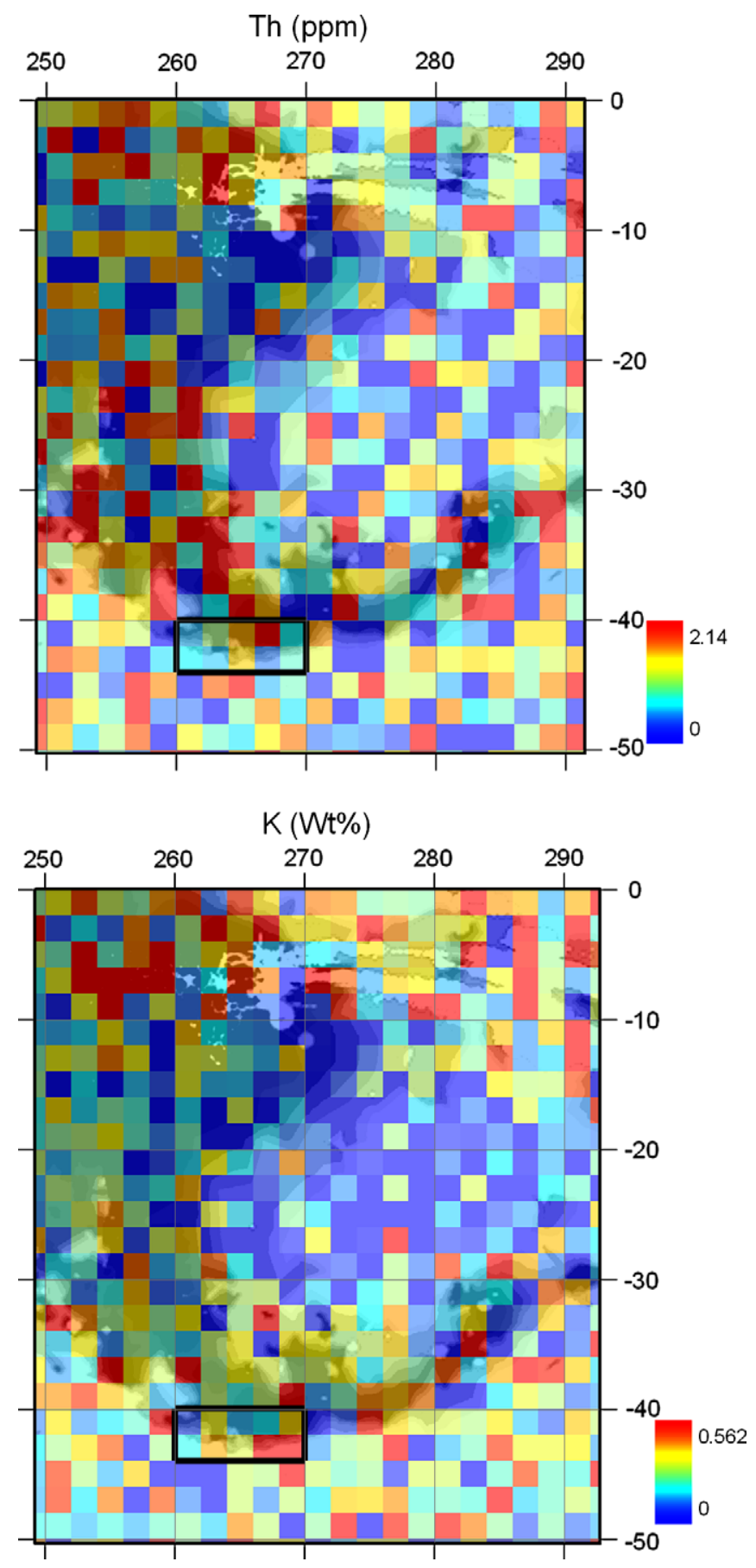

Fig. 10. Maps showing abundances of potassium and thorium based on $2^{\circ} \times 2^{\circ}$ data grids of GRS measurements (Boynton et al., 2007), superimposed on MOLA topography. The box indicates pixels including our study area. It is cleat the dispersion in data values, as well as the possible influence of the surrounding plains on our study area. 


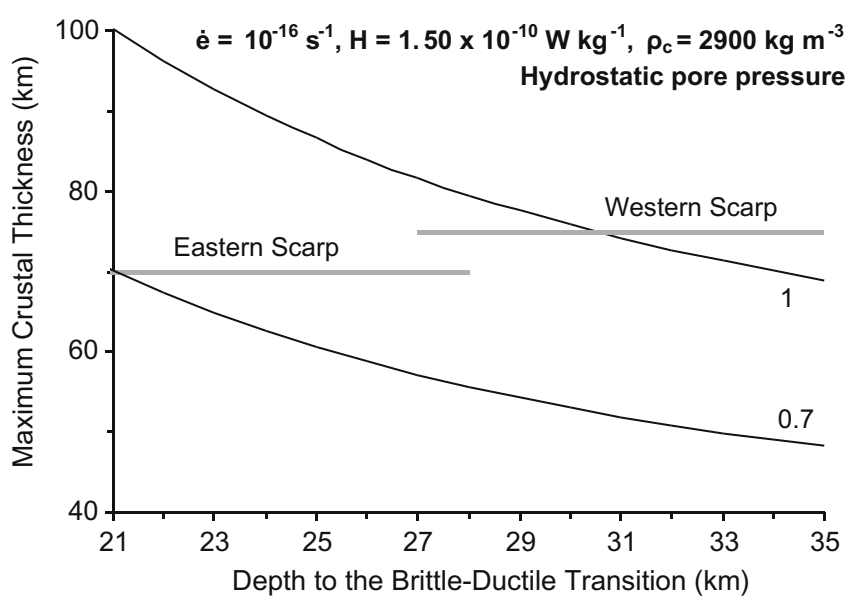

Fig. 11. Maximum permitted crustal thicknesses beneath Thaumasia highlands (solid curves) for $\rho_{c} H t_{c l} / F=1$ and 0.7 , calculate as in Fig. 9 but considering hydrostatic pore pressure and a heat production rate of $1.50 \times 10^{-10} \mathrm{~W} \mathrm{~kg}^{-1}$.

of the spacecraft, $\sim 450 \mathrm{~km}$ (Boynton et al., 2004, 2007). Thus, geologic terrains surrounding the mountain range would contribute to the GRS signature (for more information, see Boynton et al., 2004, 2007).

If we consider a study area between 40 and $44^{\circ} \mathrm{S}$ and between 260 and $270^{\circ} \mathrm{E}$ (which includes both the western and eastern scarp), the $2^{\circ} \times 2^{\circ}$ data grids of Boynton et al. (2007) only include 10 pixel points (see Fig. 10), which give average abundances of 3150 and $0.54 \mathrm{ppm}$ for potassium and thorium, respectively. Similarly, $5^{\circ} \times 5^{\circ}$ grids based on a refined modeling of GRS data (Hahn and McLennan, 2008) include only two pixels in our study area, giving average values of 3180 and $0.59 \mathrm{ppm}$ for potassium and thorium, respectively (B.C. Hahn, personal communication, 2008). Thus, the statistical reliability of the abundance values obtained for our study area is weak, and global averages may be valid for the Warrego rise region.

Fig. 11 shows maximum permitted crustal thicknesses calculated using potassium and thorium abundances of 3150 and $0.54 \mathrm{ppm}$, respectively (giving a heat production rate of $1.50 \times 10^{-10} \mathrm{~W} \mathrm{~kg}^{-1}$ for $3.7 \mathrm{Ga}$ ), along with hydrostatic pore pressure (calculated as the ratio between water and crustal density), in order to provide generous upper limits in the results. Maximum permitted crustal thicknesses are increased, and they are consistent with crustal thickness inferred for the location of eastern scarp, and for the location of western scarp and a brittle-ductile transition $30 \mathrm{~km}$ deep at most. However, if the mantle heat flow/ surface heat flow ratio was at the time of scarp formation higher than 0.3 of the surface heat low (i.e., $\rho_{c} H t_{c l} / F<0.7$ ), as predicted by thermal history models, then the thickness of a homogeneous crust is lower than the inferred local crustal thicknesses: In this case the crust must be stratified for whichever combination of parameters.

The actual rheology of crustal rocks at Warrego rise is also unclear. The use of a diabase rheology is based on the usual view of a basaltic martian crust (e.g., Taylor and McLennan, 2009). As above justified, we have used a somewhat wet diabase rheology in our calculations, but the use of a drier diabase rheology would increase the obtained heat flows and maximum crustal thicknesses. The results are very similar if the rheology of Shelton and Tullis (1981) for partly dried diabase is used: maximum permitted crustal thicknesses are at most $2 \mathrm{~km}$ thicker than those obtained for the nominal rheology used in the present work. If flow laws for dry diabases of Mackwell et al. (1998) are used, the maximum permitted crustal thickness is $\sim 90-150 \mathrm{~km}$, exceeding the lower limit in
Warrego rise. However, even for the stronger rheology of Mackwell et al. (1998) and the lowest $\mathrm{K}$ and Th abundances, the crust must be stratified if the mantle heat flow/surface heat flow ratio is higher than 0.54 and 0.38 at eastern and western scarps locations, respectively. These ratios are lower than the value of 0.7 predicted by thermal history models (e.g., Hauck and Phillips, 2002). In any case, there is no clear argument to justify the use of a dry diabase rheology for early Mars, since a minute amount of water (lower than 1 percent; see Caristan, 1982) is sufficient to achieve a "wet" rheology. Moreover, the available flow laws for dry diabases (Mackwell et al., 1998) are, in fact, ultra-dry, since experimental samples were previously heavily dehydrated. Also, a dry diabase rheology is hardly consistent with the comparison among the evolution of effective elastic thickness of the lithosphere and the thermal history models for Mars (Grott and Breuer, 2007; Guest and Smrekar, 2007).

Alternatively, the rocks forming the Thaumasia highlands could be mostly felsic (ancient mountain-forming parent rock types of Thaumasia highlands, which may be coated with secondary weathering rinds or mantled by find-grained materials, are thus far unknown from an orbital-based spectroscopic vantage). In this case, the rheology would be weaker, and hence both the surface heat flow and maximum permitted crustal thicknesses would be lower. More felsic rocks could imply a higher thermal conductivity, increasing in turn the maximum permitted crustal thickness. If we make the calculations for a dry quartzite rheology (Koch et al., 1989; these authors use the term "dry" for samples as received, not dried), and a thermal conductivity of $2.5 \mathrm{~W} \mathrm{~m}^{-1} \mathrm{~K}^{-1}$ (a value frequently used for the terrestrial continental upper crust; e.g., Cermak, 1993), the maximum crustal thicknesses at the locations of the eastern and western scarps would be $\leqslant 68$ and $\leqslant 56 \mathrm{~km}$, respectively, consistent with a stratified crust.

Uncertainties in the thermal conductivity of the crust are partly related to the composition of the crust. A thermal conductivity substantially higher than the nominal value of $2 \mathrm{~W} \mathrm{~m}^{-1} \mathrm{~K}^{-1}$ is not a realistic possibility for basaltic materials (see Beardsmore and Cull, 2001), whereas possible crustal rocks with higher thermal conductivity are weaker, as above mentioned. Water or ice could fill the porosity of the upper crust, which would somewhat increase the total thermal conductivity. Water thermal conductivity is lower than that of crustal rocks and its effect should be minor. At upper crust temperatures, ice thermal conductivity is somewhat higher than the thermal conductivity of basaltic rocks, but similar to that of more felsic rocks. But ice, if present, is restricted to the upper few kilometers. Finally, an upper layer or low thermal conductivity regolith would decrease the surface heat flow.

The uncertainties in strain rate and surface temperature do not influence our conclusions. Thus, higher strain rates than those used here are likely unrealistic for Mars: $\sim 10^{-16} \mathrm{~s}^{-1}$ is a typical value for terrestrial intraplate deformation (e.g., Tesauro et al., 2007); for comparison, a strain rate of $\sim 10^{-19} \mathrm{~s}^{-1}$ has been estimated for the Tempe Terra extensional province of Mars (Wilkins et al., 2002). A higher surface temperature, which could be related to a warmer early martian climate (e.g., Fanale et al., 1992), would imply lower heat flows and permitted crustal thicknesses.

\section{Conclusions}

The results of the present work strongly suggest that the crust beneath Thaumasia highlands is chemically stratified with a heat-producing enriched upper layer, which is thinner than the whole crust. This is consistent with magmatic-driven activity proposed to have influenced the geological evolution of the Warrego rise region (e.g., Dohm et al., 2001a; Grott et al., 2007). This is also consistent with the proposal of Norman (2002), based on the 
geochemistry of martian meteorites, of an upper crust, $\leqslant 45 \mathrm{~km}$ thick (in average), enriched in light rare earth elements. In fact, for a mantle heat flow/surface heat flow ratio of $\sim 0.7$, similar to that deduced from thermal history models, our calculations obtain an upper crust of $\sim 20-30 \mathrm{~km}$, in accordance with the results of Norman (2002). The upper crust would have been formed early in the history of Mars from an undepleted mantle, and subsequent additions to the crust derived from depleted mantle sources. Our results are also consistent with a crust at most $\sim 50 \mathrm{~km}$ thick obtained by Grott (2005) from modeling of lithospheric extension at Coracis Fossae, whose formation dates from the Noachian/Early Hesperian: the remainder crustal thickness would emplaced subsequently to the fossae formation. So, this work strengthens previous work by Ruiz et al. (2006b) suggesting a differentiated crust in Solis Planum, since the calculations in this study use refined thorium and potassium abundance measurements.

Our results therefore support the Thaumasia highlands as an important target for future research, since it has significant potential to provide information clues on the evolutional history of Mars, including the chemical evolution of the martian crust.

\section{Acknowledgments}

J.R. was supported by a contract Juan de la Cierva for Earth Sciences, co-financed from the Ministerio de Ciencia e Innovación of Spain and the European Social Fund. J.M.D. was supported by the NASA Mars Data Analysis Program. We thank Trent Hare for Fig. 1 production, and Brian Hahn for facilitating corrected abundances for potassium and thorium in our study area. Also, we thank the comments and suggestions from two anonymous reviewers.

\section{References}

Acuña, M.H., 12 colleagues, 1999. Global distribution of crustal magnetization discovered by the Mars Global Surveyor MAG/ER experiment. Science 284, 790 793.

Acuña, M.H., 13 colleagues, 2001. Magnetic field of Mars: Summary of results from the aerobraking and mapping orbits. J. Geophys. Res. 106, 23403-23417.

Anderson, R.C., Dohm, J.M., Golombek, M.P., Haldemann, A., Franklin, B.J., Tanaka, K.L., Lias, J., Peer, B., 2001. Significant centers of tectonic activity through time for the western hemisphere of Mars. J. Geophys. Res. 106, 20,563-20,585.

Anguita, F., Fernández, C., Cordero, G., Carrasquilla, S., Anguita, J., Núñez, A., Rodríguez, S., García, J., 2006. Evidences for a Noachian-Hesperian orogeny in Mars. Icarus 185, 331-357.

Ansan, V., Mangold, N., 2006. New observations of Warrego Valles, Mars: Evidence for precipitation and surface runoff. Planet. Space Sci. 54, 219-242.

Arkani-Hamed, J., 2003. Thermoremanent magnetization of the martian lithosphere. J. Geophys. Res. 108. doi:10.1029/2003JE002049.

Baker, V.R., Maruyama, S., Dohm, J.M., 2007. Tharsis superplume and the geological evolution of early Mars. In: Yuen, D.A., Maruyama, S., Karato, S-I., Windley, B.F. (Eds.), Superplumes: Beyond Plate Tectonics. Springer, Berlin, pp. 507-523.

Beardsmore, G.R., Cull, J.P., 2001. Crustal Heat Flow: A Guide to Measurement and Modelling. Cambridge University Press, Cambridge.

Bonner, J.L., Blackwell, D.D., Herrin, E.T., 2003. Thermal constraints on earthquake depths in California. Bull. Seismol. Soc. Am. 93, 2333-2354.

Boynton, W.V., 28 colleagues, 2004. The Mars Odyssey gamma-ray spectrometer instrument suite. Space Sci. Rev. 110, 37-83.

Boynton, W.V., 27 colleagues, 2007. Concentration of $\mathrm{H}, \mathrm{Si}, \mathrm{Cl}, \mathrm{K}, \mathrm{Fe}$, and $\mathrm{Th}$ in the low- and mid-latitude regions of Mars. J. Geophys. Res. 110, E12S99. doi:10.1029/2007JE002887.

Caristan, Y., 1982. The transitions from high temperature creep to fracture in Marylan diabase. J. Geophys. Res. 87, 6781-6790.

Cermak, V., 1993. Lithospheric thermal regimes in Europe. Phys. Earth Planet. Int. 79, 179-193.

Clifford, S.M., 1993. A model for the hydrologic and climatic behaviour of water on Mars. J. Geophys. Res. 98, 10,973-11,016.

Connerney, J.E.P., Acuña, M.H., Wasilewski, P.J., Kletetschka, G., Ness, N.F., Rème, H., Lin, R.P., Mitchell, D.L., 1999. The global magnetic field of Mars and implication for crustal evolution. Science 284, 790-793.

Connerney, J.E.P., Acuña, M.H., Ness, N.F., Kletetschka, G., Mitchell, D.L., Lin, R.P., Rème, H., 2005. Tectonic implications of Mars crustal magnetism. Science 102 14970-14975.

Dohm, J.M., Tanaka, K.L., 1999. Geology of the Thaumasia region, Mars: Plateau development, valley origins, and magmatic evolution. Planet. Space Sci. 47, 411-431.
Dohm, J.M., Anderson, R.C., Tanaka, K.L., 1998. Digital structural mapping of Mars. Astron. Geophys. 39, 3, 3.20-3, 3.22.

Dohm, J.M., Ferris, J.C., Baker, V.R., Anderson, R.C., Hare, T.M., Strom, R.G., Barlow, N.G., Tanaka, K.L., Klemaszewski, J.E., Scott, D.H., 2001a. Ancient drainage basin of the Tharsis region, Mars: Potential source for outflow channel systems and putative oceans or paleolakes. J. Geophys. Res. 106, 32,943-32,958.

Dohm, J.M., Tanaka, K.L., Hare, T.M., 2001b. Geologic map of the Thaumasia region of Mars. US Geol. Survey Map I-2650.

Dohm, J.M., Baker, V.R., Maruyama, S., Anderson, R.C., 2007. Traits and evolution of the Tharsis superplume Mars. In: Yuen, D.A., Maruyama, S., Karato, S.-I. Windley, B.F. (Eds.), Superplumes: Beyond Plate Tectonics. Springer, Berlin, pp. 523-537.

Dohm, J.M., 13 colleagues, 2009. Claritas rise, Mars: Pre-Tharsis Magmatism? J. Volcanol. Geotherm. Res. 5. doi:10.1016/j.jvolgeores.2009.03.012.

Fairén, A.G., Dohm, J.M., Baker, V.R., de Pablo, M.A., Ruiz, J., Ferris, J.C., Anderson, R.C., 2003. Episodic flood inundations of the northern plains of Mars. Icarus 165, 53-67.

Fanale, F.P., Postawko, S.E., Pollack, J.B., Carr, M.H., Pepin, R.O., 1992. Mars: Epocha climate change and volatile history. In: Kieffer, H.H., Jakosky, B.M., Snyder, C.W. Matthews, M.S. (Eds.). Mars. Univ. of Arizona Press, Tucson, pp. 1135-1179.

Fraeman, A.A., Mustard, J.F., Ehlmann, B.L., Roach, L.H., Milliken, R.E., Murchie, S.L. 2009. Evaluating models of crustal cooling using CRISM observations of impact craters in Terra Tyrrhena and Noachis Terra. Proc. Lunar Planet. Sci. Conf. 40. Abstract 2320.

Grott, M., 2005. Late crustal growth on Mars: Evidence from lithospheric extension. Geophys. Res. Lett. 32, L23201. doi:10.1029/2005GL024492.

Grott, M., Breuer, D., 2007. The evolution of the martian elastic lithosphere and implications for crustal and mantle rheology. Icarus 186, 517-526.

Grott, M., Hauber, E., Werner, S.C., Kronberg, P., Neukum, G., 2005. High heat flux on ancient Mars: Evidence from rift flank uplift at Coracis Fossae. Geophys. Res. Lett. 32, L21201. doi:10.1029/2005GL023894.

Grott, M., Hauber, E., Werner, S.C., Kronberg, P., Neukum, G., 2007. Mechanical modelling of thrust faults in the Thaumasia region, Mars, and implications for the Noachian heat flux. Icarus 186, 517-526.

Guest, A., Smrekar, S., 2007. New constraint on the thermal and volatile evolution of Mars. Phys. Earth Planet. Inter. 164, 161-176.

Gulick, V.C., Baker, V.R., 1989. Fluvial valleys and martian palaeoclimates. Nature 341, 514-516.

Hahn, B.C., McLennan, S.M., 2008. Martian surface heat production and crustal heat flow from Mars Odyssey gamma-Ray spectrometry. Proc. Lunar Planet. Sci. Conf. 39. Abstract 2032

Hanna, J.C., Phillips, R.J., 2005. Hydrological modeling of the martian crust with application to the pressurization of aquifers. J. Geophys. Res. 110, E01004. doi:10.1029/2004JE002330.

Hartmann, W.K., Neukum, G., 2001. Cratering chronology and the evolution of Mars. Space Sci. Rev. 96, 165-194.

Hauber, E., Kronberg, P., 2005. The large Thaumasia Graben on Mars: Is it a rift? J Geophys. Res. 110, E07003. doi:10.1029/2005JE002407.

Hauck, S.A., Phillips, R.J., 2002. Thermal and crustal evolution of Mars. J. Geophys. Res. 107. doi:10.1029/2001JE001801.

Head, J.W., Greeley, R., Golombek, M.P., Hartmann, W.K., Hauer, E., Jaumann, R., Masson, P., Neukum, G., Nyquist, L.E., Carr, M.H., 2001. Geological processes and evolution. Space Sci. Rev. 96, 263-292.

Kiefer, W.S., 2008. Exploring early Tharsis: Gravity observations of radiating dike systems in the Thaumasia region of Mars. Proc. Lunar Planet. Sci. Conf. 39. Abstract 1671.

Kieffer, H.H., Martin, T.Z., Peterfreund, A.R., Jakosky, B.M., Miner, E.D., Palluconi, F.D. 1977. Thermal and albedo mapping of Mars during the Viking primary mission. Geophys. Res. 82, 4249-4291.

Koch, P.S., Christie, J.M., Ord, A., George, R.P., 1989. Effect of water on the rheology of experimentally deformed quartzite. J. Geophys. Res. 94, 13,966-13,975.

Konopliv, A.S., Yoder, C.F., Standish, E.M., Yuan, D.N., Sjogren, W.L., 2006. A global solution for the Mars static and seasonal gravity, Mars orientation, Phobos and Deimos masses, and Mars ephemeris. Icarus 182, 23-50.

Kronberg, P., Hauber, E., Grott, M., Werner, S.C., Schäfer, T., Gwinner, K., Giese, B. Masson, P., Neukum, G., 2007. Acheron Fossae, Mars: Tectonic rifting, volcanism, and implications for lithospheric thickness. J. Geophys. Res. 112, E04005. doi:10.1029/2002JE001854.

Mackwell, S.J., Zimmerman, M.E., Kohlstedt, D.L., 1998. High-temperature deformation of dry diabase with application to tectonics on Venus. J Geophys. Res. 103, 975-984.

McGovern, P.J., Solomon, S.C., Smith, D.E., Zuber, M.T., Simons, M., Wieczorek, M.A Phillips, R.J., Neumann, G.A., Aharonson, O., Head, JW., 2002. Localized gravity/ topography admittance and correlation spectra on Mars: Implications for regional and global evolution. J. Geophys. Res. 107, 5136. doi:10.1029/ 2002JE001854.

McGovern, P.J. Solomon, S.C. Smith, D.E.,Zuber, M.T. Simons, M., Wieczorek, M.A Phillips, R.J., Neumann, G.A., Aharonson, O., Head, J.W., 2004. Correction to Localized gravity/topography admittance and correlation spectra on Mars: Implications for regional and global evolution. J. Geophys. Res. 109, E07007. doi:10.1029/2004JE002286.

McKenzie, D., Barnett, D.N., Yuan, D.L., 2002. The relationship between martian gravity and topography. Earth Planet. Sci. Lett. 195, 1-16.

McLennan, S.M., 2003. Large-ion lithophile element fractionation during the early differentiation of Mars and the composition of the martian primitive mantle. Meteor. Planet. Sci. 38, 895-904. 
Neumann, G.A., Zuber, M.T., Wieczorek, M.A., McGovern, P.J., Lemoine, F.G., Smith, D.E., 2004. The crustal structure of Mars from gravity and topography. J. Geophys. Res. 109, E08002. doi:10.1029/2004JE002262.

Neumann, G.A., Lemoine, F.G., Smith, D.E., Zuber, M.T., 2008. Marscrust3-A crustal thickness inversion from recent MRO gravity solutions. Proc. Lunar Planet. Sci. Conf. 39. Abstract 2167.

Norman, M.D., 2002. Thickness and composition of the martian crust revisited: Implications of an ultradepleted mantle with $\mathrm{Nd}$ isotopic composition like that of QUE94201. Proc. Lunar Planet. Sci. Conf. 33. Abstract 1175.

Parker, R.L., 1972. The rapid calculation of potential anomalies. Geophys. J.R. Astron. Soc. 31, 447-455

Parmentier, E.M., Zuber, M.T., 2007. Early evolution of Mars with mantle compositional stratification or hydrothermal crustal cooling. J. Geophys. Res. 112, E02007. doi:10.1029/2005JE002626.

Parmentier, E.M., Mustard, J.F., Ehlmann, B.L., Roach, 2008. Deep hydrothermal circulation and implications for the early crustal compositional and thermal evolution of Mars. Proc. Lunar Planet. Sci. Conf. 39. Abstract 1544.

Ranalli, G., 1997. Rheology of the lithosphere in space and time. Geol. Soc. Spec. Pub. $121,19-37$.

Ruiz, J., McGovern, P.J., Tejero, R., 2006a. The early thermal and magnetic state of the cratered highlands of Mars. Earth Planet. Sci. Lett. 241, 2-10.

Ruiz, J., Tejero, R., McGovern, P.J., 2006b. Evidence for a differentiated crust at Solis Planum, Mars, from lithospheric strength and heat flow. Icarus 180, 308-313.

Ruiz, J., Fernández, C., Gomez-Ortiz, D., Dohm, J.M., López, V., Tejero, R., 2008. Ancient heat flow, crustal thickness, and lithospheric mantle rheology in the Amenthes region, Mars. Earth Planet. Sci. Lett. 270, 1-12.

Schultz, R.A., Watters, T.R., 2001. Forward mechanical modeling of the Amenthes Rupes thrust fault on Mars. Geophys. Res. Lett. 28, 4659-4662.

Schulze-Makuch, D., Dohm, J.M., Fan, C., Fairén, A.G., Rodriguez, J.A.P., Baker, V.R. Fink, W., 2007. Exploration of hydrothermal targets on Mars. Icarus 189, 308324.

Scott, D.H., Dohm, J.M., Rice, J.W., 1995. Map of Mars showing channels and possible paleolake basins. USGS Misc. Inv. Ser. Map I-2461 (1:30,000,000).

Shelton, G., Tullis, J.A., 1981. Experimental flow laws for crustal rocks. Eos Trans. AGU 62, 396.
Smith, D.E., 23 colleagues, 2001. Mars Orbiter Laser Altimeter: Experiment summary after the first year of global mapping of Mars. J. Geophys. Res. 106, $23,689-23,722$

Tanaka, K.L., Dohm, J.M., Lias, J.H., Hare, T.M., 1998. Erosional valleys in the Thaumasia region of Mars: Hydrothermal and seismic origins. J. Geophys. Res. $103,31,407-31,419$.

Taylor, G.J., 22 colleagues, 2006. Bulk composition and early differentiation of Mars. J. Geophys. Res. 111, E03S10. doi:10.1029/2005JE002645. [Printed 112(E3), 2007].

Taylor, S.R., McLennan, S.M., 2009. Planetary crusts: Their composition, origin and evolution. Cambridge University Press, Cambridge.

Tesauro, M., Kaban, M.K., Cloetingh, S.A.P.L., Hardebol, N.J., Beekman, F., 2007. 3D strength and gravity anomalies of the European lithosphere. Earth Planet. Sci. Lett. 263, 56-73.

Travis, B.J., Rosenberg, N.D., Cuzzi, J.N., 2003. On the role of widespread subsurface convection in bringing liquid water close to Mars' surface. J. Geophys. Res. 108, 8040. doi:10.1029/2002JE001877.

Turcotte, D.L., Willemann, R.J., Haxby, W.F., Norberry, J., 1981. Role of membrane stresses in the support of planetary topography. J. Geophys. Res. 86, 3951-3959.

Van Schmus, W.R., 1995. Natural radioactivity of the crust and mantle. In: Ahrens, T.J. (Ed.), Global Earth physics: A handbook of physical constants. AGU Reference Shelf 1, American Geophysical Union, Washington, D.C., pp. 283-291.

Wieczorek, M.A., 2007. Gravity and topography of the terrestrial planets. Treat. Geophys. 10, 165-206. doi:10.1016/B978-044452748-6/00156-5.

Wieczorek, M.A., Phillips, R.J., 1998. Potential anomalies on a sphere: Applications to the thickness of the lunar crust. J. Geophys. Res. 103, 1715-1724.

Wieczorek, M.A., Zuber, M.T., 2004. Thickness of the martian crust: Improved constraints from geoid-to-topography ratios. J. Geophys. Res. 109, E01009. doi:10.1029/2003JE002153.

Wilkins, S.J., Schultz, R.A., Anderson, R.C., Dohm, J.M., Dawers, N.H., 2002. Deformation rates from faulting at the Tempe Terra extensional province, Mars. Geophys. Res. Lett. 29. doi:10.1029/2002GL015391.

Williams, J.P., Nimmo, F., Moore, W.B., Paige, D.A., 2008. The formation of Tharsis on Mars: What the line-of-sight gravity is telling us. J. Geophys. Res. 113, E10011. doi:10.1029/2007JE003050.

Zuber, M.T., 14 colleagues, 2000. Internal structure and early thermal evolution of Mars from Mars Global Surveyor. Science 287, 1788-1793. 